\title{
Effects of Fasting on Tissue Contents of Coenzyme $A$ and Related Intermediates in Rats
}

\author{
FLOOR A. JENNISKENS, KATRINA S. JOPPERI-DAVIS, LAUREN C. WALTERS, \\ ERICA N. SCHORR, LYNETTE K. ROGERS, STEPHEN E. WELTY, AND CHARLES V. SMITH \\ Center for Developmental Pharmacology and Toxicology, Columbus Children's Research Institute, and \\ Division of Neonatology, Department of Pediatrics, Ohio State University, Columbus, Ohio 43205, U.S.A.
}

\begin{abstract}
Exposure of rats and mice to hyperoxia decreases lung coenzyme A (CoASH) contents, with a decrease of $50 \%$ observed in adult male Fischer-344 rats exposed to $>95 \% \mathrm{O}_{2}$ for $48 \mathrm{~h}$. Decreases in lung CoASH levels are not accompanied by increases in contents of the mixed glutathione disulfide of CoA, as might be expected of a primary oxidative stress on CoASH status. Animals exposed to hyperoxia exhibit decreased food intake, and the present studies were to test the hypothesis that fasting would decrease lung CoASH contents, thereby suggesting a mechanism for the effects of hyperoxia. Adult male Fischer344 rats were examined after 0,24 , or $48 \mathrm{~h}$ of fasting $(n=5,6$, and 6 , respectively). Fasting for 24 or $48 \mathrm{~h}$ did not affect lung CoASH levels or lung weights, despite 6 and $12 \%$ losses in body weight. Lung glutathione concentrations (nanomoles per gram of tissue) and contents (nanomoles per whole organ) and glutathione disulfide contents were 10 to $20 \%$ lower in rats fasted for $48 \mathrm{~h}$ than in fed rats. Liver weights and glutathione and glutathione disulfide contents and concentrations were 30 to $70 \%$ lower in rats fasted for 24 or $48 \mathrm{~h}$ than in fed rats. Hepatic $\mathrm{CoASH}$ concentrations increased during fasting, but hepatic contents of CoASH remained remarkably constant. Liver protein contents (milligrams of protein per whole organ) decreased after 24 and $48 \mathrm{~h}$ of fasting, but protein concentrations (milligrams of
\end{abstract}

\section{ABSTRACT}

protein per gram of tissue) were higher in rats fasted $48 \mathrm{~h}$ than in fed rats. Overall, glutathione, glutathione disulfide, and protein contents in liver and skeletal muscle decreased with fasting, but significant changes in CoASH contents were not observed. Diminished food intake in animals does not explain the effects of hyperoxia on lung CoASH contents. CoASH and derived thioesters participate in many cellular functions, and if depletion of lung CoASH during hyperoxia proves to be relevant to mechanisms of lung injury, support of mechanisms needed to sustain CoA levels could be helpful in prematurely born infants and in adults. (Pediatr Res 52: 437-442, 2002)

$\quad$ Abbreviations
GSH, glutathione
GSSG, glutathione disulfide
GR, glutathione reductase
CoASH, coenzyme A
CoASSG, coenzyme A-glutathione mixed disulfate
BUN, blood urea nitrogen
ALT, alanine aminotransferase
NEM, $n$-ethylmaleimide
HB, homogenate buffer

In the care of patients with pulmonary insufficiency, administration of supplemental oxygen is an important therapy. This treatment, however, increases pulmonary production of potentially injurious oxygen metabolites (1) and can cause serious adverse effects, as has been observed in the lungs of experimental animals and humans exposed to elevated oxygen tensions (2-5). Extrapulmonary effects of hyperoxia are observed $(6,7)$ and may contribute more to hyperoxic lung injury than is appreciated at present. Cellular injury is observed when the rates of generation of the reactive oxygen species exceed the capacities of the antioxidant defense mechanisms, such as with

Received November 8, 2001; accepted March 8, 2002.

Correspondence and reprint requests: Charles Vincent Smith, Ph.D., Columbus Children's Research Institute, 700 Children's Drive, Columbus, OH 43205, U.S.A.; e-mail: smithcv@chi.osu.edu

DOI: 10.1203/01.PDR.0000025346.04153.80 therapeutic exposures to $>21 \% \mathrm{O}_{2}(2,8-10)$, or when the functions of the antioxidant defense mechanisms are deficient, compromised, or developmentally unprepared, such as in prematurely born infants $(4,11-14)$.

GSH is an important component of antioxidant defenses in the lung and other tissues (15). GSH is a cofactor in the reduction by glutathione peroxidases of $\mathrm{H}_{2} \mathrm{O}_{2}$ and other hydroperoxides. In the reduction of hydroperoxides, GSH is oxidized to GSSG, which can $S$-thiolate protein thiols, thereby altering protein structures and functions, with the potential to alter cell viability. Reduction of GSSG by GR limits accumulation of GSSG and $S$-thiolation of protein thiols. This glutathione redox cycle plays an essential protective role against reactive oxygen species $(16,17)$, and concentrations of GSH and GSSG and their ratios (18) frequently are measured as indicators of the magnitude of an oxidative stress. Although 
depletion of GSH, GSH precursor pools, or GSH-dependent antioxidant functions increases susceptibility to hyperoxic lung injury (19-23), exposure to hyperoxia does not deplete lung GSH in experimental animals (19-24). This apparent paradox might be a result of compartmentalization of GSSG, such as has been characterized for mitochondria (25). Siess and coworkers (26) have estimated that $80 \%$ of CoASH in rat liver is intramitochondrial.

As CoASH and CoASSG undergo thiol-disulfide exchange reactions with GSH and GSSG (27), in a manner analogous to that described above for protein thiols, CoASH and CoASSG could offer useful biomarkers that can be measured with minimum ex vivo artifacts and may reasonably be expected to reflect intramitochondrial thiol redox status (27). In recent studies, we have observed that lung CoASH contents decreased by $50 \%$ in adult male Fischer-344 and Sprague-Dawley rats exposed to $>95 \% \mathrm{O}_{2}$ for $48 \mathrm{~h} \mathrm{(28)}$ and observed similar effects in C57/B16 mice (29). The decreases in lung CoASH contents were not accompanied by increases in CoASSG levels, as might be expected of a primary oxidative stress on $\mathrm{CoASH}$ status. Lung GSSG levels increased modestly after exposure to $>95 \% \mathrm{O}_{2}$ for $48 \mathrm{~h}$, but lung GSH levels were not affected.

Animals exposed to hyperoxia exhibit decreased food intake (7), and fasting alone decreased tissue GSH levels in liver, kidney, and lung (30-32). Deneke and coworkers (21-23) showed that a low-protein diet exacerbated oxygen toxicity, but cysteine supplementation of the same low-protein diets returned susceptibility to hyperoxia to normal, whereas equimolar amounts of leucine were without effect. Deneke et al. (21-23) concluded that exacerbation of hyperoxia lung injury was caused by insufficient supplies of cysteine or methionine, leading to an inability to increase GSH levels during hyperoxia. Stabler and coworkers (33) recently found that very premature baboons may have decreased cysteine availability or increased cysteine utilization, similar to the abnormalities previously shown in both preterm and term human infants in respiratory distress (34). In addition, humans with acute or chronic pulmonary diseases who are most likely to require treatment with high concentrations of oxygen in a postsurgical setting or in an intensive care unit are often unable to maintain an adequate food intake and exhibit protein and caloric malnutrition (35).

The present studies were designed to test the hypothesis that fasting would decrease lung CoASH contents, thereby suggesting a mechanism for the effects of hyperoxia on lung CoASH contents that we have observed. We also determined the effects of fasting for 24 or $48 \mathrm{~h}$ on concentrations and contents of GSH, GSSG, CoASH, CoASSG, and protein in lungs, livers, kidneys, and skeletal muscle (quadriceps) of adult male Fischer-344 rats.

\section{METHODS}

Animals. The Children's Research Institute's Institutional Animal Care and Use Committee approved all animal studies. The studies used 9-wk-old Fischer-344 male rats weighing 182-211 g obtained from Harlan Sprague-Dawley (Indianapolis, IN, U.S.A.). The rats were maintained in environmentally controlled animal rooms at $22-24^{\circ} \mathrm{C}$, and the rats were allowed to adapt to their environment for $5 \mathrm{~d}$ before study. At $\mathrm{d} 1$, all rats were weighed and marked randomly, and food was taken from the first six rats. The animals were housed on wood chip bedding, and the cages were changed each morning and afternoon to minimize coprophagia. All animals were permitted free access to water throughout the experiment. At d 2, the food was taken from the next six rats. At d 3, all rats were killed and the samples were taken. The rats were anesthetized with 200 $\mathrm{mg} / \mathrm{kg}$ of intraperitoneal pentobarbital i.p., a midline thoracotomy was performed, and intracardiac blood samples were obtained, using heparinized syringes. Plasma was separated and stored at $4^{\circ} \mathrm{C}$. Immediately after the blood was collected, the organs (lung, liver, kidneys, and quadriceps muscle) were freeze-clamped with liquid nitrogen-cooled aluminum blocks and stored initially in liquid nitrogen and later at $-80^{\circ} \mathrm{C}$ until processed for measurements. A portion of liver and a portion of the right kidney were fixed in formaldehyde.

Reagents. All reagents were obtained from Sigma Chemical Co. (St. Louis, MO, U.S.A.). The assay kits for quantitation of creatinine, BUN, and ALT activities were obtained from Sigma Diagnostics (St. Louis, MO, U.S.A.).

Measurements. A piece of frozen tissue $(0.1 \mathrm{~g})$ was weighed and ground to a powder with a mortar and pestle cooled with liquid nitrogen. The powder was added to $1 \mathrm{~mL}$ of $100 \mathrm{mM}$ $\mathrm{NaPO}_{4}$ buffer, $\mathrm{pH} 7.4$, which contained $5 \mathrm{mM}$ EDTA, and the mixture was homogenized with a Dounce homogenizer. For measurement of GSSG, CoASH, and CoASSG, $10 \mu \mathrm{L}$ of $1 \mathrm{M}$ NEM was added to the buffer before addition of the tissue powder. The homogenates were centrifuged at $13,000 \times g$ for $10 \mathrm{~min}$ at $5^{\circ} \mathrm{C}$, and the supernatants were removed for analysis.

GSH and GSSG quantitation. GSH levels in supernatants were measured by GR enzyme recycling methods as described previously (16). For GSH measurements, the supernatants were diluted, lung 1:100, liver 1:200, kidney 1:25, and muscle $1: 200$. Then, $30-\mu \mathrm{L}$ aliquots of the supernatants were added to wells of a 96-well microtiter plate and mixed with $120 \mu \mathrm{L}$ of $100 \mathrm{mM} \mathrm{NaPO} /$ EDTA buffer (HB), $0.125 \mathrm{U}$ of GR (Sigma

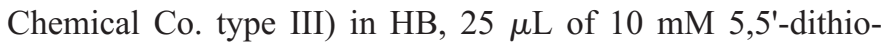
bis(2-nitrobenzoic acid), and $50 \mu \mathrm{g}$ of NADPH in HB. The plate was read immediately with a microtiter spectrophotometer (Dynatech Technologies, Inc., Chantilly, VA, U.S.A.) to measure GSH concentrations.

For GSSG measurements, $200 \mu \mathrm{L}$ of the supernatants were passed at one drop/s through C18 Sep-Pak cartridges (Waters, Milford, MA, U.S.A.) and eluted with $800 \mu \mathrm{L}$ of $100 \mathrm{mM} \mathrm{HB}$. Then, $200-\mu \mathrm{L}$ aliquots of the eluents were added to wells of a 96-well microtiter plate and mixed with GR, 5,5'-dithio-bis(2nitrobenzoic acid), and NADPH, as described for GSH quantitation.

Standards of GSH (0-300 pmol per assay) and GSSG (0-200 pmol per assay) were prepared, and levels of GSH and GSSG in samples were calculated from the standard curves derived from the rates of increased absorbance at $412 \mathrm{~nm}$.

CoASH and CoASSG quantitation. Homogenates were prepared similar to the method described above for GSSG quantitation, but proteins were precipitated with equal volumes of $4 \% \mathrm{HClO}_{4}$ before analyses. CoASH and CoASSG contents 
were determined by HPLC using methods derived from the report of Baker and Schooley (36). The CoA species were separated on a Zorbax (MACMOD, Chadds Ford, PA, U.S.A.) SB- $\mathrm{C}_{18}$ column using the following mobile phases: $10 \mathrm{mM}$ tetrabutylammonium hydrogen sulfate $(\mathrm{pH} 5.0)$ and $10 \%$ methanol (A), and $10 \mathrm{mM}$ tetrabutylammonium hydrogen sulfate (pH 5.0) and 85\% methanol (B). The gradient was 6 min at $100 \% \mathrm{~A}$, followed by $45 \mathrm{~min}$ to reach $70 \% \mathrm{~B}$ at a minus 2 gradient; quantitation of CoASH and CoASSG was by peak areas from UV detection at $254 \mathrm{~nm}$.

Standards were prepared in $0.1 \mathrm{M} \mathrm{NaPO}_{4}(\mathrm{pH} \mathrm{3.0)}$ ) and 10 $\mathrm{mM}$ NEM and were acidified with equal volumes of $4 \%$ $\mathrm{HClO}_{4}$, in the range of 0 to $1 \mathrm{nmol}$ for CoASH-NEM and 0 to $0.1 \mathrm{nmol}$ for CoASSG. CoA species were quantitated by comparison of peak areas from samples with peak areas measured in experimentally derived standard curves.

Protein quantitation. Protein concentrations were determined according to the technique described by Bradford (37).

Creatinine quantitation. Plasma creatinine concentrations were determined at 515-540 nm, using creatinine kit procedure no 555-A and a DU 640 spectrophotometer (Beckman Coulter Inc., Fullerton, CA, U.S.A.).

BUN quantitation. BUN concentrations were determined at $500 \mathrm{~nm}$ using BUN kit procedure no 535.

ALT quantitation. Plasma ALT activities were determined at $340 \mathrm{~nm}$ using Sigma Chemical Co. assay kit procedure no. 59-UV.

Statistics. Data were assessed statistically by one-way ANOVA and Student-Newman-Keuls post hoc tests, with the exception that comparisons of body weights before and after fasting were assessed by paired $t$ tests, with differences noted at $p<0.05$. All data are expressed as means \pm SEM. All statistical comparisons were performed using SPSS version 10.0 (SPSS Inc., Chicago, IL, U.S.A.).

\section{RESULTS}

The initial body weights of the animals assigned to each of the three study groups were not different (Table 1). There were no deaths in rats during fasting for up to $48 \mathrm{~h}$. Rats fasted for 24 and $48 \mathrm{~h}$ lost, on average, 6 and 12\%, respectively, of their initial body weights (Table 1). Fed animals gained minimal weight $(1.3 \%)$. No effects of fasting on lung or kidney weights were observed. In contrast, liver and quadriceps weights from the fasted animals were markedly lower than the corresponding tissues in the fed controls. Liver weights were $29 \%$ lower after $24 \mathrm{~h}$ and $43 \%$ lower after $48 \mathrm{~h}$ of fasting than were liver weights of control animals, whereas quadriceps weights decreased 18 and $39 \%$ over the same time span.

Lungs of rats that were fasted for $48 \mathrm{~h}$ demonstrated modest (10 to $20 \%$ ) decreases in concentrations (expressed in micromoles or nanomoles per gram of tissue) and contents (expressed in micromoles or nanomoles per whole organ) of GSH (Fig. 1, $A$ and $B$ ) and lower total contents of GSSG (Fig. 1B). No effects of fasting on lung concentrations or total lung contents of CoASH and CoASSG were observed (Fig. 1, C and $D)$.

Fasting for 24 and $48 \mathrm{~h}$ decreased the liver concentrations of GSH (Fig. 2A). This effect of fasting was magnified by the losses of liver weight, such that the total liver contents of GSH were diminished by fasting even more dramatically (Fig. $2 B$ ). Hepatic GSSG concentrations and contents changed in parallel with GSH, and GSH/GSSG ratios did not change (Table 2). In contrast, hepatic CoASH concentrations (Fig. 2C) in the fasted animals were almost twice those observed in the fed animals, but the total liver contents of CoASH (Fig. 2D) remained remarkably constant. Hepatic CoASSG concentrations and total contents of CoASSG increased after $24 \mathrm{~h}$ of fasting and decreased from 24 to $48 \mathrm{~h}$ of fasting (Fig. 2, $C$ and $D$ ). $\mathrm{CoASH} / \mathrm{CoASSG}$ ratios decreased after $24 \mathrm{~h}$ of fasting and increased from 24 to $48 \mathrm{~h}$ (Table 2).

Fasting for 24 or $48 \mathrm{~h}$ had no effect on kidney GSH, GSSG, $\mathrm{CoASH}$, and CoASSG concentrations or contents (data not shown).

No effects of fasting on concentrations of GSH or GSSG in quadriceps muscle were observed (Fig. $3 \mathrm{~A}$ ), but fasting for 24 or $48 \mathrm{~h}$ caused declines in the total contents of GSH and GSSG per quadriceps muscle (Fig. 3B). Concentrations and total contents of CoASH or CoASSG in the fasted animals were not different from fed animals (Fig. 3, $C$ and $D$ ). The protein concentrations per gram of muscle did not change, but the protein contents per muscle decreased after $48 \mathrm{~h}$ of fasting (Fig. 4B). Hepatic protein concentrations increased after $48 \mathrm{~h}$ of fasting; however, the total contents of protein in livers decreased after 24 and $48 \mathrm{~h}$ of fasting (Fig. $4 A$ ).

After 24 and $48 \mathrm{~h}$ of starvation, BUN concentrations decreased (Fig. 5A). Plasma creatinine concentrations increased in the first $24 \mathrm{~h}$ of fasting, but returned to the levels observed in the fed animals from 24 to $48 \mathrm{~h}$ (Fig. 5B). Plasma ALT activities were higher in animals fasted for $48 \mathrm{~h}$ than in the fed controls (Fig. 5C), but increases in plasma ALT activities from 12 to $15 \mathrm{U} / \mathrm{L}$ are unlikely to signal any meaningful disease.

Table 1. Effects of fasting on body and organ weights

\begin{tabular}{|c|c|c|c|c|c|c|c|}
\hline Fast (h) & $\begin{array}{l}\text { Body weight } \\
\text { fasting (g) }\end{array}$ & $\begin{array}{l}\text { Body weight } \\
\text { fasting (g) }\end{array}$ & $\begin{array}{l}\text { Weight gain } \\
\text { (g) }\end{array}$ & Livers (g) & Lungs (g) & $\begin{array}{c}\text { Left } \\
\text { kidneys (g) }\end{array}$ & $\begin{array}{l}\text { Quadriceps } \\
\text { muscles (g) }\end{array}$ \\
\hline 0 & $199 \pm 4$ & $201 \pm 3 t$ & $2.6 \pm 1.9^{\S}$ & $8.68 \pm 0.38^{\|}$ & $1.18 \pm 0.03$ & $0.77 \pm 0.01$ & $2.33 \pm 0.13^{\pi}$ \\
\hline 24 & $196 \pm 2$ & $184 \pm 2 \ddagger$ & $-11.3 \pm 0.6^{\S}$ & $6.12 \pm 0.27^{\|}$ & $1.12 \pm 0.02$ & $0.73 \pm 0.03$ & $1.91 \pm 0.09^{\natural}$ \\
\hline
\end{tabular}

Fischer-344 adult male rats were fasted for 0,24 , or $48 \mathrm{~h}$. After the rats were sacrificed, the indicated organs were freeze-clamped and weighted. Data are expressed as means \pm SEM, $n=5-6$ per group, assessed statistically by one-way ANOVA and Student-Newman-Keuls post hoc tests, with differences noted at $p<0.05$. Comparisons of body weights and fasting were assessed by paired $t$ tests, with differences noted at $p<0.05$. Data marked with corresponding common symbols are different from each other. 

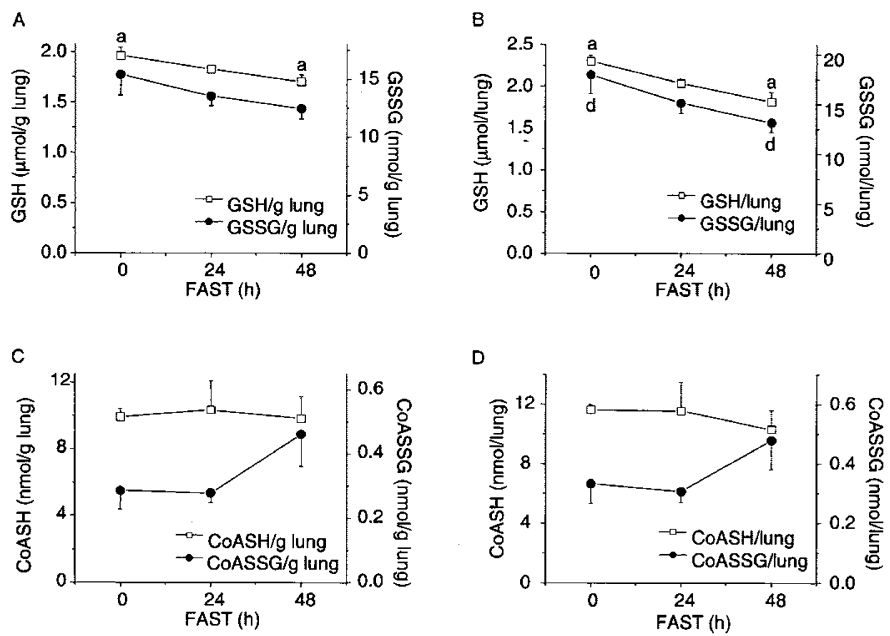

Figure 1. Effects of fasting on lung concentrations and contents of GSH, GSSG, CoASH, and CoASSG. Fischer-344 male rats were fasted for 0, 24, or $48 \mathrm{~h}$, and GSH and GSSG $(A, B)$ and CoASH and CoASSG $(C, D)$ concentrations (per gram of lung; $A, C$ ) and contents (per whole lung; $B, D$ ) were determined. Data are expressed as mean \pm SEM, $n=5-6$ per group, assessed statistically by one-way ANOVA and Student-Newman-Keuls post hoc tests, with differences noted at $p<0.05$. Data marked with corresponding common letters are different from each other.
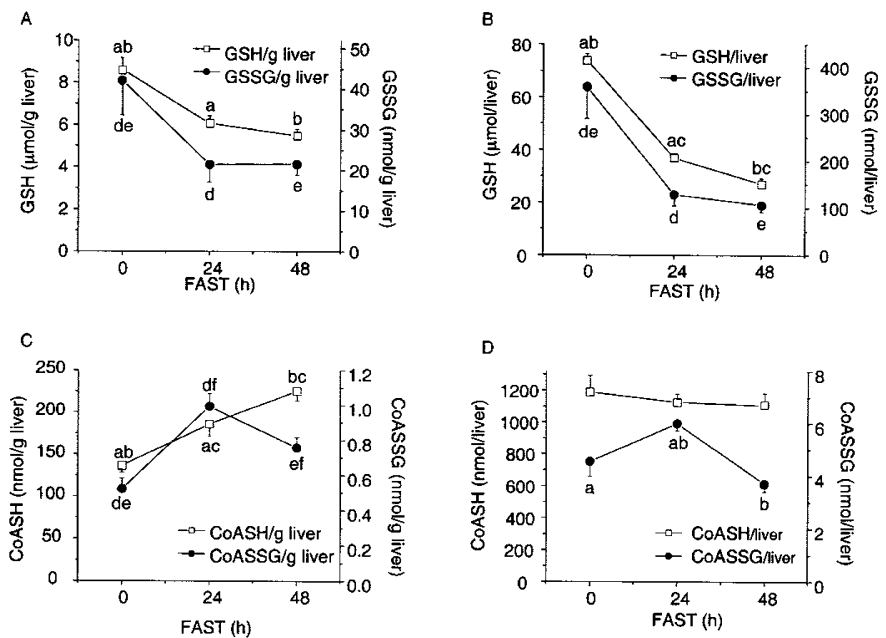

Figure 2. Effects of fasting on liver concentrations and contents of GSH, GSSG, CoASH, and CoASSG. Fischer-344 male rats were fasted for 0, 24, or $48 \mathrm{~h}$, and hepatic GSH and GSSG $(A, B)$ and CoASH and CoASSG $(C, D)$ concentrations (per gram of liver; $A, C$ ) and contents (per whole liver; $B, D$ ) were determined. Data are expressed as mean \pm SEM, $n=5-6$ per group, assessed statistically by one-way ANOVA and Student-Newman-Keuls post hoc tests, with differences noted at $p<0.05$. Data marked with corresponding common letters are different from each other.

\section{DISCUSSION}

The decreases in lung CoASH contents we observed in previous studies of rats exposed to $>95 \% \mathrm{O}_{2}$ (28) do not seem to be mediated by diminished food intake caused by exposure of the animals to hyperoxia. Thus, the effects of hyperoxia on lung CoASH contents are more attributable to other effects of hyperoxia. The losses in CoASH are not offset by increases in CoASSG, as might have been expected with a simple redox shift, but the data presently available do suggest that the decreases in lung CoASH levels represent some form of sec- ondary oxidant stress response. Fasting for $48 \mathrm{~h}$ caused declines in lung GSH concentrations and contents and in GSSG contents, in contrast with what we have observed in exposure of these animals to hyperoxia (28).

Although decreases in lung contents of GSH in animals exposed to hyperoxia have not been observed in most studies reported to date $(21,22,28,38,39)$, fasting or limiting dietary protein intake can potentiate or accelerate the emergence of lung damage in animals exposed to hyperoxia $(21,39-41)$. The increase in animal sensitivity to normobaric hyperoxia was paralleled by attenuation or prevention of the increases in lung GSH levels usually observed in animals fed normal diets after 24 to $48 \mathrm{~h}$ of normobaric hyperoxia. Deneke and coworkers $(21,23)$ reported that normal resistance to hyperoxia and increases in lung GSH levels could be restored in proteinrestricted animals by supplementation of protein-deficient diets with cysteine, cystine, or methionine, but not by comparable supplementation with leucine. The apparent contradictions suggested by the effects of protein deprivation and amino acid supplementation with the absence of primary effects of hyperoxia on lung GSH levels thus suggested either that responses of hyperoxic lung injury to divalent sulfur availability were mediated by compartmental or cell type-specific effects on lung GSH or on extrapulmonary GSH pools, or that the pathophysiologic effects of protein deprivation on the responses to hyperoxia were influenced by effects on species other than GSH.

The liver is the major source for GSH in the plasma, and plasma GSH is the major source for cysteine for protein and intracellular GSH synthesis in extrahepatic tissues (31). The marked decreases in hepatic GSH contents in rats fasted for 24 or $48 \mathrm{~h}$ (Fig. 2) thus indicate markedly compromised status of this important determinant of the animal's antioxidant defense functions and ability to respond to additional demands, such as might be driven by hyperoxia. The decreases in hepatic contents of GSH and protein in the fasted rats are impressive and presumably reflect adaptations that serve to sustain extrahepatic cysteine and GSH levels. Stabler and coworkers (33) recently discovered that very premature baboons may have decreased cysteine availability or increased cysteine utilization that are similar to the abnormalities previously shown in both preterm and term human infants in respiratory distress (34). However, the minimal changes in lung GSH contents observed in the fasted rats in the present studies (Fig. 1) suggest considerable reserve capacity in preserving extrahepatic GSH homeostasis in these animals. The absence of decreases in lung GSH contents in animals exposed to hyperoxia alone dampens the enthusiasm for consideration of liver GSH status effects in animals exposed to hyperoxia. However, we have observed time-dependent increases in hepatic CoASSG contents in mice exposed to hyperoxia (29), which indicates an oxidant stress response in the livers of animals exposed to hyperoxia. In addition to the direct effect of hyperoxia on hepatic CoASSG contents, cysteine is a precursor for CoASH synthesis, and compromised hepatic synthesis and export of GSH could, in principle, decrease extrahepatic synthesis of CoASH. Diminished lung tissue CoASH contents we have observed in rats (28) and mice (29) exposed to hyperoxia, although not replicated by fasting alone, might be exacerbated by exposure to 
Table 2. Effects of fasting on GSH/GSSG and CoASH/CoASSG ratios

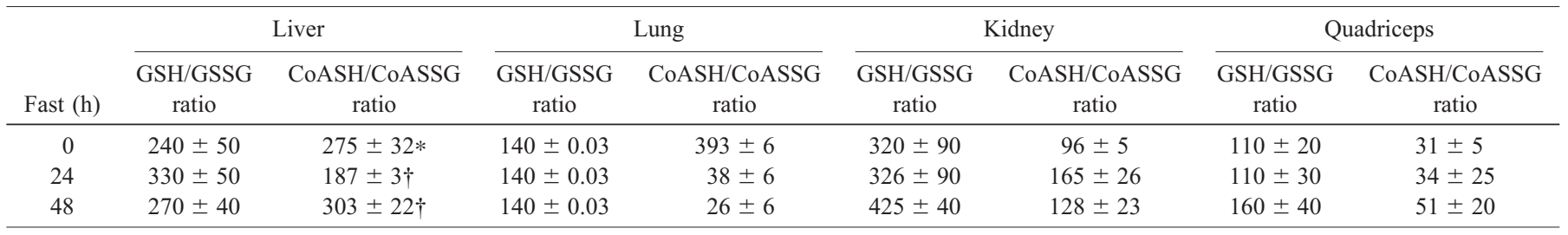

Fischer-344 male rats were fasted for 0, 24, or $48 \mathrm{~h}$; GSH, GSSG, CoASH, and CoASSG concentrations were determined in the tissues indicated, and the ratios were calculated. Data are expressed as mean \pm SEM, $n=5-6$ per group, assessed statistically by one-way ANOVA and Student-Newman-Keuls post hoc tests, with differences noted at $p<0.05$. Data marked with corresponding common symbols are different from each other.
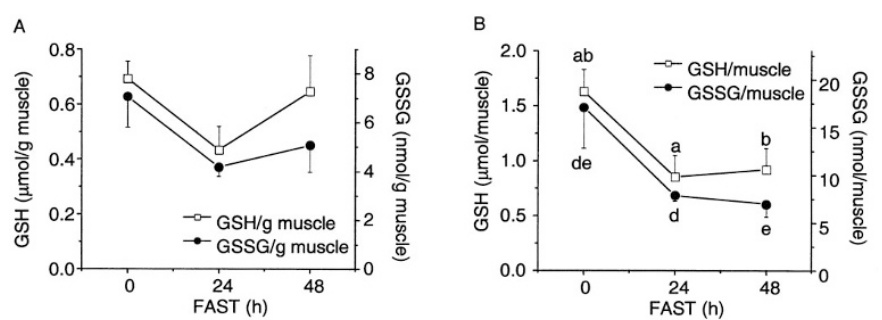

C
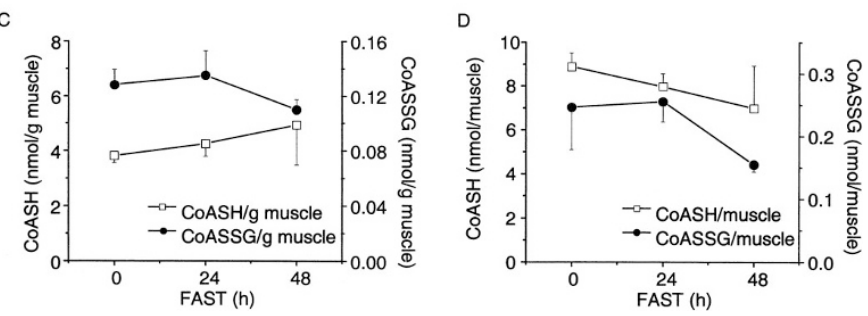

Figure 3. Effects of fasting on quadriceps muscle concentrations and contents of GSH, GSSG, CoASH, CoASSG. Fischer-344 male rats were fasted for 0, 24 , or $48 \mathrm{~h}$, and muscle GSH and $\operatorname{GSSG}(A, B)$ and CoASH and CoASSG $(C$, $D$ ) concentrations (per gram of muscle; $A, C$ ) and contents (per whole muscle; $B, D)$ were determined. Data are expressed as mean \pm SEM, $n=5-6$ per group, assessed statistically by one-way ANOVA and Student-Newman-Keuls post hoc tests, with differences noted at $p<0.05$. Data marked with corresponding common letters are different from each other.
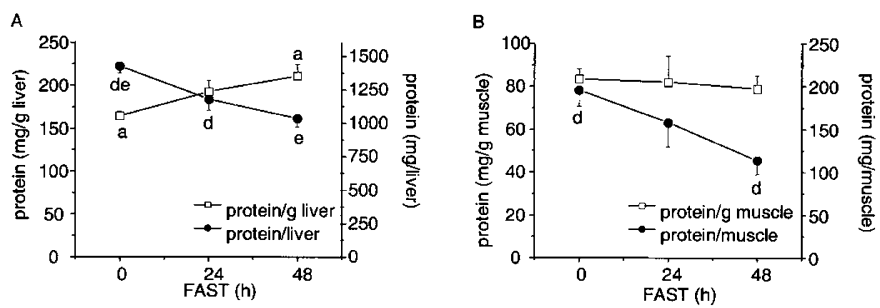

Figure 4. Effects of fasting on protein concentrations and contents of quadriceps muscle and liver. Fischer-344 male rats were fasted for 0, 24, or $48 \mathrm{~h}$, and liver $(A)$ and muscle $(B)$ protein concentrations and contents in tissue homogenates were determined. Data are expressed as mean \pm SEM, $n=5-6$ per group, assessed statistically by one-way ANOVA and Student-NewmanKeuls post hoc tests, with differences noted at $p<0.05$. Data marked with corresponding common letters are different from each other.

metabolic stresses driven by exposure to hyperoxia. Humans with acute or chronic pulmonary diseases who are most likely to require treatment with high concentrations of oxygen in a postsurgical setting or in an intensive care unit often may not maintain adequate food intake for sustaining normal or adequate CoASH supplies (35). If CoASH depletion in lungs of animals exposed to hyperoxia proves to be relevant to lung injury caused in human patients exposed to hyperoxia, support
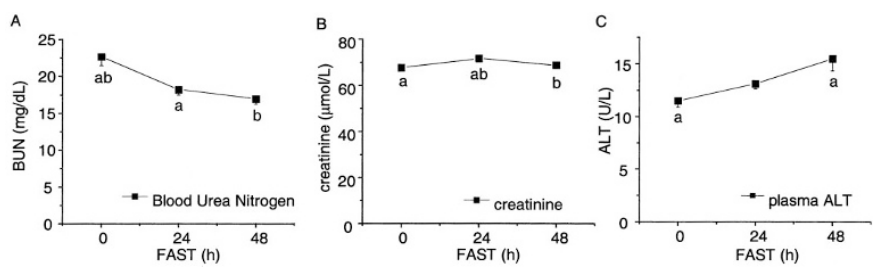

Figure 5. Effects of fasting on the plasma concentrations of BUN (A) and creatinine (B) and plasma ALT activities (C). Fischer-344 male rats were fasted for 0,24 , or $48 \mathrm{~h}$, and BUN and creatinine concentrations and ALT activities were determined in the plasma. Data are expressed as mean $\pm \mathrm{SEM}$, $n=5-6$ per group, assessed statistically by one-way ANOVA and StudentNewman-Keuls post hoc tests, with differences noted at $p<0.05$. Data marked with corresponding common letters are different from each other.

of mechanisms needed to sustain CoA levels could be helpful in prematurely born infants as well as in adults.

\section{REFERENCES}

1. Freeman BA, Crapo JD 1981 Hyperoxia increases oxygen radical production in rat lungs and lung mitochondria. J Biol Chem 256:10986-10992

2. Freeman BA, Tanswell AK 1985 Biochemical and cellular aspects of pulmonary oxygen toxicity. Adv Free Radic Biol Med 1:133-164

3. Crapo JD 1986 Morphologic changes in pulmonary oxygen toxicity. Annu Rev Physiol 48:721-731

4. Frank L 1991 Developmental aspects of experimental pulmonary oxygen toxicity. Free Radic Biol Med 11:463-494

5. Crapo JD, Barry BE, Foscue HA, Shelburne J 1980 Structural and biochemical changes in rat lungs occurring during exposures to lethal and adaptive doses of oxygen. Am Rev Respir Dis 122:123-143

6. Roberts RJ, Rendak I, Bucher JR 1983 Lipid peroxidation in the newborn rat: influence of fasting and hyperoxia on ethane and pentane in expired air. Dev Pharmacol Ther 6:170-178

7. Khatsenko OG, Sindhu RK, Kikkawa Y 1997 Undernutrition during hyperoxic exposure induces CYP2E1 in rat liver. Arch Toxicol 71:684-689

8. Jamieson D, Chance B, Cadenas E, Boveris A 1986 The relation of free radical production to hyperoxia. Annu Rev Physiol 48:703-719

9. Turrens JF, Freeman BA, Crapo JD 1982 Hyperoxia increases $\mathrm{H}_{2} \mathrm{O}_{2}$ release by lung mitochondria and microsomes. Arch Biochem Biophys 217:411-421

10. Wispe JR, Roberts RJ 1987 Molecular basis of pulmonary oxygen toxicity. Clin Perinatol 14:651-666

11. Smith CV, Hansen TN, Martin NE, McMicken HW, Elliott SJ 1993 Oxidant stress responses in premature infants during exposure to hyperoxia. Pediatr Res 34:360-366

12. deLemos RA, Coalson JJ 1992 The contributions of experimental models to our understanding of the pathogenesis and treatment of bronchopulmonary dysplasia. Clin Perinatol 19:521-539

13. Yam J, Frank L, Roberts RJ 1978 Oxygen toxicity: comparison of lung biochemical responses in neonatal and adult rats. Pediatr Res 12:115-119

14. Tanswell AK, Freeman BA 1984 Pulmonary antioxidant enzyme maturation in the fetal and neonatal rat. I. Developmental profiles. Pediatr Res 18:584-587

15. Susanto I, Wright SE, Lawson RS, Williams CE, Deneke SM 1998 Metallothionein, glutathione, and cystine transport in pulmonary artery endothelial cells and NIH/3T3 cells. Am J Physiol 274:L296-L300

16. Adams Jr JD, Lauterburg BH, Mitchell JR 1983 Plasma glutathione and glutathione disulfide in the rat: regulation and response to oxidative stress. J Pharmacol Exp Ther 227:749-754

17. White CW, Jackson JH, McMurtry IF, Repine JE 1988 Hypoxia increases glutathione redox cycle and protects rat lungs against oxidants. J Appl Physiol 65:2607-2616

18. White CW, Mimmack RF, Repine JE 1986 Accumulation of lung tissue oxidized glutathione (GSSG) as a marker of oxidant induced lung injury. Chest 89:1115-1135

19. Langley SC, Kelly FJ 1992 Effect of food restriction on hyperoxia-induced lung injury in preterm guinea pig. Am J Physiol 263:L357-L362 
20. Smith LJ, Anderson J 1992 Oxygen-induced lung damage: relationship to lung mitochondrial glutathione levels. Am Rev Respir Dis 146:1452-1457

21. Deneke SM, Gershoff SN, Fanburg BL 1983 Potentiation of oxygen toxicity in rats by dietary protein or amino acid deficiency. J Appl Physiol 54:147-151

22. Deneke SM, Lynch BA, Fanburg BL 1985 Transient depletion of lung glutathione by diethyl maleate enhances oxygen toxicity. J Appl Physiol 58:571-574

23. Deneke SM, Lynch BA, Fanburg BL 1985 Effects of low protein diets or feed restriction on rat lung glutathione and oxygen toxicity. J Nutr 115:726-732

24. Jenkinson SG, Black RD, Lawrence RA 1988 Glutathione concentrations in rat lung bronchoalveolar lavage fluid: effects of hyperoxia. J Lab Clin Med 112:345-351

25. Smith CV, Jones DP, Guenthner TM, Lash LH, Lauterburg BH 1996 Compartmentation of glutathione: implications for the study of toxicity and disease. Toxicol Appl Pharmacol 140:1-12

26. Siess EA, Brocks DG, Wieland OH 1978 Distribution of metabolites between the cytosolic and mitochondrial compartments of hepatocytes isolated from fed rats. Hoppe-Seyler's Z Physiol Chem 359:785-798

27. Gilbert HF 1995 Thiol/disulfide exchange equilibria and disulfide bond stability. Methods Enzymol 251:8-28

28. O’Donovan DJ, Rogers LK, Kelley DK, Welty SE, Ramsay PL, Smith CV 2002 CoASH and CoASSG levels in lungs of hyperoxic rats as potential biomarkers of intramitochondrial oxidant stresses Pediatr Res 51:346-353

29. Wong YL, Smith CV, McMicken HW, Rogers LK, Welty SE 2001 Mitochondrial thiol status in the liver is altered by exposure to hyperoxia. Toxicol Lett 123:179-193

30. Liu PT, Ioannides C, Symons AM, Parke DV 1993 Role of tissue glutathione in prevention of surgical trauma. Xenobiotica 23:899-911
31. Lauterburg BH, Adams JD, Mitchell JR 1984 Hepatic glutathione homeostasis in the rat: efflux accounts for glutathione turnover. Hepatology 4:586-590

32. Smith LJ, Friedman H, Anderson J 1988 Hyperoxic lung injury in mice: effect of neutrophil depletion and food deprivation. J Lab Clin Med 111:449-458

33. Stabler SP, Morton RL, Winski SL, Allen RH, White CW 2000 Effects of parenteral cysteine and glutathione feeding in a baboon model of severe prematurity. Am J Clin Nutr $72: 1548-1557$

34. White CW, Stabler SP, Allen RH, Moreland S, Rosenberg AA 1994 Plasma cysteine concentrations in infants with respiratory distress. J Pediatr 125:769-777

35. Tremper JC 1981 Nutritional assessment of individuals with chronic obstructive pulmonary disease. Am Rev Respir Dis 123:118S

36. Baker FC, Schooley DA 1981 Separation of S-acyl-CoA thioesters and related compounds by reversed-phase ion-pair chromatography. Methods Enzymol 72:41-52

37. Bradford MM 1976 A rapid and sensitive method for the quantitation of microgram quantities of protein utilizing the principle of protein-dye binding. Anal Biochem $72: 248-254$

38. Rusakow LS, White CW, Stabler SP $1993 \mathrm{O}_{2}$-induced changes in lung and storage pool thiols in mice: effect of superoxide dismutase. J Appl Physiol 74:989-997

39. Smith LJ, Anderson J, Shamsuddin M, Hsueh W 1990 Effect of fasting on hyperoxic lung injury in mice: the role of glutathione. Am Rev Respir Dis 141:141-149

40. Frank L, Sosenko IRS 1988 Undernutrition as a major contributing factor in the pathogenesis of bronchopulmonary dysplasia. Am Rev Respir Dis 138:725-729

41. Frank L, Groseclose E 1982 Oxygen toxicity in newborn rats: the adverse effects of undernutrition. J Appl Physiol 53:1248-1255 